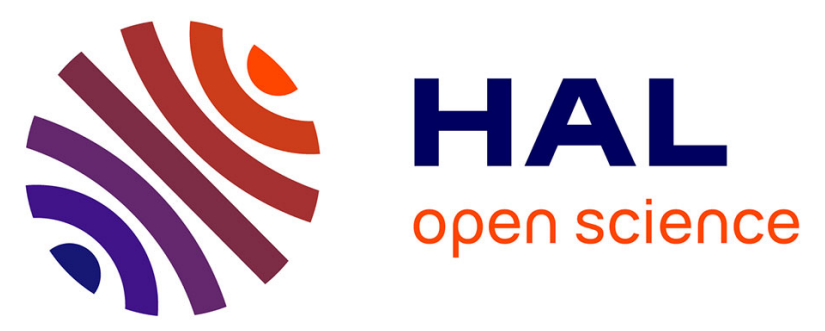

\title{
High hopes: lower risk of death due to mental disorders and self-harm in a century-long US Olympian cohort compared with the general population
}

Stephanie Duncombe, Hirofumi Tanaka, Quentin de Larochelambert, Julien Schipman, Jean-François Toussaint, Juliana Antero

\section{To cite this version:}

Stephanie Duncombe, Hirofumi Tanaka, Quentin de Larochelambert, Julien Schipman, Jean-François Toussaint, et al.. High hopes: lower risk of death due to mental disorders and self-harm in a centurylong US Olympian cohort compared with the general population. British Journal of Sports Medicine, 2020, bjsports-2020-102624. 10.1136/bjsports-2020-102624 . hal-03261365

\section{HAL Id: hal-03261365 \\ https://hal-insep.archives-ouvertes.fr/hal-03261365}

Submitted on 15 Jun 2021

HAL is a multi-disciplinary open access archive for the deposit and dissemination of scientific research documents, whether they are published or not. The documents may come from teaching and research institutions in France or abroad, or from public or private research centers.
L'archive ouverte pluridisciplinaire HAL, est destinée au dépôt et à la diffusion de documents scientifiques de niveau recherche, publiés ou non, émanant des établissements d'enseignement et de recherche français ou étrangers, des laboratoires publics ou privés. 


\title{
High Hopes: Lower Risk of Death due to Mental Disorders and Self-Harm in a Century-Long US Olympian Cohort compared with the general population
}

\author{
Stephanie Duncombe $M P H^{1}$, Hirofumi Tanaka Ph.D. ${ }^{2}$, Quentin De Larochelambert $M S c^{1}$, Julien Schipman $M S c^{1}$, \\ Jean-François Toussaint M.D. Ph.D. ${ }^{1,3,4}$, Juliana Antero PT, Ph.D. ${ }^{l}$ \\ ${ }^{1}$ Institute for Research in Medicine and Epidemiology of Sports (IRMES, EA7329), the French National Sports \\ Institute (INSEP), Paris, France \\ ${ }^{2}$ The University of Texas at Austin, Austin, Texas USA \\ ${ }^{3}$ Université de Paris, Paris, France \\ ${ }^{4}$ CIMS, Hôtel-Dieu, AP-HP, Paris, France
}

Word Count: 2,999

\author{
Corresponding Author: \\ Juliana Antero \\ IRMES, Institut de Recherche bio-Médicale et d'Epidémiologie du Sport \\ INSEP, Institut National du Sport, de l'Expertise et de la Performance \\ 11 Avenue Tremblay \\ Paris, France \\ 75012 \\ E-mail: juliana.antero@insep.fr
}




\section{Summary Box}

\section{What are the new findings?}

- US Olympians had a $32 \%$ (SMR $=0.68,95 \%$ CI 0.49 to 0.91$)$ lower risk of death compared with the general population for studied mental disorders, eating disorders, and suicide.

- Whilst elite athletes are still vulnerable to mental disorders and suicides, it is possible that high-level training has an impact on longevity related to these causes.

\section{How might it impact on clinical practice in the future?}

- Elite athletes, who can appear invincible to some, are not immune to these disorders and an open, stigmafree dialogue is necessary on the topic of mental disorders and suicides. 


\begin{abstract}
Objective: As previous studies showed that elite athletes have rates of anxiety, depression, substance abuse, and eating disorders higher than or comparable to the general population, our aim was to determine the risk of death due to these prominent mental disorders, substance abuse, and suicides among US Olympians compared with the general population.
\end{abstract}

Methods: All female $(n=2,301)$ and male $(n=5,823)$ US Olympians who participated in the summer or winter Games between 1912 and 2012 were followed until 2016. The National Death Index certified their vital statuses and causes of death. We applied the years-saved (YS) method to quantify differences in the probability of death for 1) anxiety, depression, and self-harm and 2) substance abuse and eating disorders in comparison to the general population. We performed a Standard Mortality Ratio (SMR) analysis.

Results: US Olympians had a 32\% (SMR $=0.68,95 \%$ CI 0.49 to 0.91$)$ lower risk of death compared with the general population for both categories of mental disorders, resulting in a longevity advantage of 0.21 YS (95\% CI 0.14 to 0.29 ) in group 1 and 0.12 years (95\% CI 0.08 to 0.15 ) in group 2. There were no significant differences between medalists and non-medalists, but findings varied by sports. Most sports had significantly lower risks of deaths except for shooting, which showed a trend toward a higher risk through suicide by firearm.

Conclusion: Olympians have a lower risk of death, favouring an increased longevity compared with the general population for mental disorders, substance abuse, and suicides.

Funding: None

Word Count: 248

Keywords: elite athletes; Americans; mental disorders; suicide; years-lost 


\section{Introduction}

There is a paucity of data on mental disorders in Olympic athletes, and the long-term consequences remain largely unknown. Additionally, comparisons with the general population continue to be challenging due to the absence of appropriate reference groups [1], but studies have estimated the prevalence of mental disorders and substance abuse to be higher or comparable to the general population [1-4]. The most prevalent disorders in the Olympian cohort are anxiety, depression, eating disorders, and substance abuse [1-4]. Differences exist between former and current athletes [1,2], along with those suffering from recurring injuries or performance difficulties [2]. Varying rates of disorders have also been reported based on the sport practiced [4]. Therefore, longitudinal follow-up and sport-based analyses are critical issues to investigate.

The risk of death due to these mental disorders is poorly understood. Suicide in elite athletes is plausible due to a variety of predispositions, including the stress, psychological traits, retirement, and injuries [5]. However, organized sport is also capable of protecting individuals against hopelessness, while leading to increased self-esteem and social connectedness [5,6]. Previous studies within the National Collegiate Athlete Association and National Football League have shown a lower suicide rate compared with the general population [7-9]. However, no studies have examined the risk of death due to suicides in the overall Olympic population, except for whether steroids affect the risk in Swedish male athletes [10]. US Olympians comprise the largest cohort by country within the games. They are a particularly interesting cohort to study due to the higher rate of mid-life death from drug overdoses, alcohol abuse, suicides, and organ diseases faced by Americans in general [11].

Accordingly, the main aims of this investigation were to determine the risk of death due to prominent mental disorders, substance abuse, and suicides among US Olympians compared to the general population and to quantify the longevity losses or gains. Within the Olympian population, we also sought to determine if a difference existed by sport, or between medalists and non-medalists.

2. Methods

2.1 Data Collection

We included all the female and male US Olympians that participated in either the summer or winter Olympic Games between 1912 and 2012. Biographical information (full name, date and place of birth, and date(s) of Olympic Games participation) was collected from reliable databases including official Olympic competitors' lists, birth registers, newspapers, published obituaries, etc., and is available online (www.sports-reference.com/olympics) [12]. We excluded Olympians if their date and/or place of birth were missing. We confirmed the vital status of every Olympian through the National Death Index (NDI), which provides the underlying cause of death starting from 1979 when the death register began. Currently, the NDI lists causes until 2016, which is the endpoint of our study. We obtained the cause of death through public sources (the internet, media coverage, or the national sports federation) for deaths that occurred before 1979. To ensure the quality of results was maintained, a sensitivity analysis was performed to determine the effect of causes of death found via internet on the final results.

\subsection{Mental Disorder and Suicide Definition}

We defined death by a mental disorder or suicide as those listed with a primary cause linked to substance abuse, anxiety, depression, eating disorder, or self-harm based on the International Classification of Diseases (ICD) codes at the time of death provided through the NDI. Coding of these causes used the version of that was in effect at the time of death (8th revision before 1978, 9th revision between 1979 and 1999, and 10th revision after 2000) (supplementary file).We focused on these causes as they have been identified as the most prevalent mental disorders among elite athletes [1,2]. We created two subcategories: 1) deaths from anxiety, depression, or self-harm and 2) deaths from substance abuse or an eating disorder. 


\subsection{Cohort of Reference: General Population}

Overall mortality rates for the general population was obtained through the national life tables, available by the Berkeley Mortality database (http://bmd.mortality.org/) and the Human Mortality database (https://www.mortality.org/) which provides death rates since 1900. Death rates for the underlying causes studied were obtained via the WONDER database provided by the US Center for Disease Control and Prevention (wonder.cdc.gov/) which provides death rates since 1968 [13]. Since no specific death rates exists before 1968, we extrapolated deaths rates back until 1912 based on the trend for the period between 1968 and 2016. A sensitivity analysis was conducted to verify the effect of this extrapolation by limiting the analysis to the period without extrapolation.

\subsection{Data Analyses}

To compare the probability of death from the analyzed causes with the general population we applied the years-saved method previously used in a cohort of French Olympians [14]. First, we estimated the cumulative probability of dying for Olympians using the Aalen-Johansen estimator. Then, the expected probability of death was calculated for the referents in the general population: for each individual in our study, the general population mortality values of individuals of the same sex and born in the same calendar year were considered. We used their values for each age from the time of participation in the Olympics until the end of follow-up. Through this, all the comparisons with the general population were adjusted by sex, birth date, and period of follow-up. The average number of years lost/saved was then estimated by calculating the difference of the areas below these two curves.

The years-saved method can be applied to cause specific death as it is based on the competing risks model [15]. This considers the potential that an athlete can die from any cause of death and not just from the studied causes. It maintains the rationality that the sum of years lost/saved by each cause corresponds to the total number of years lost/saved. This is preferable over a standard survival analysis where deaths outside of the causes studied are treated as censored - as if the individual was alive - and therefore could introduce bias [15-17]. For US Olympians, analyses began at an athlete's first Olympics and lasted until either the athlete's age at death, age 90 (chosen to allow comparison with other studies [16]), or our study's end-point. For comparisons with the general population, the Olympians follow-up was synchronized with the mortality rates of the general population. Therefore, the comparisons with the general population use the exact same periods of follow-up as the Olympians and take in account only the morality rates in the general population where people have the same age and sex.

To quantify differences in the overall mortality rates and to conduct the sensitivity analysis, we performed a Standard Mortality Ratio (SMR) analysis. The SMR allows comparison of the mortality of the studied cohort with that of the total population containing this cohort, with age, sex and period adjustment. In practical terms, SMR is the ratio between the number of deaths observed in the Olympic cohort and the number of expected deaths if the Olympians had the same death rates as the US population.

For sports that had over 100 total general deaths (athletics, rowing, swimming, fencing, and shooting), we completed sub-analyses comparing the risk of death in each sport between Olympians and general population for those who died from self-harm, anxiety, or depression. We also compared the risk of death between medalists and non-medalists within the two subcategories to see if performance influenced the outcome.

We set confidence intervals at $95 \%$ and we considered a 2 -tailed $\mathrm{p}$-value $<0.05$ statistically significant. $\mathrm{R}$ software (V3.5.3; The R Foundation for Statistical Computing, Vienna, Austria) was used for our statistical analyses.

\subsection{Ethical Approval and Patient and Public Involvement}

This study received ethics approval from the Institutional Review Board at the University of Texas at Austin (201503-0035). Data analyses and protection strictly adhered to the confidential data control plan based on the specifications set by the NDI. Neither athletes nor the public were involved the in the design of this study. 
3. Results

Between 1912 and 2012, 8,134 athletes (2,301 women and 5,833 men) participated in either the summer or winter Games. Ten were excluded from our analysis due to a missing birthplace or birthdate. In total, 2,309 deaths occurred throughout the century of follow-up, of which 44 primary cause were attributed to a mental disorder or suicide. The mean age of death for the 44 athletes was $57.5 \pm 17.6$ years. Eight deaths from mental disorders were not certified by the NDI since they occurred between 1920 and 1965. The sensitivity analysis performed show no significant difference in the magnitude nor direction of the results when limiting the analysis to the period with NDI certification and without mortality rates extrapolation. By restraining the analysis to the certified period, for the two groups of mental disorders, we found a mortality reduction among Olympians of $43 \%$ ( $\mathrm{SMR}=0.57,95 \%$ CI 0.42 to 0.77 ). By extending the analysis to the period with non-certified data the mortality reduction is of $32 \%$ (SMR $=0.68,95 \%$ CI 0.49 to 0.91 ). YS analysis includes the whole data set.

\subsection{Deaths Attributed to Self-Harm, Anxiety, and Depression}

Thirty deaths ( 2 women, 28 men) were due to anxiety, depression, or self-harm. The most frequent mechanism was suicides due to firearms (Table 1). US Olympians had a significantly lower probability of death by these causes in comparison to the general population with 0.21 YS $(95 \%$ CI 0.14 to 0.29$)$ (Figure 1AB). For the 5 sports analysed, differences between sports were uncovered (Figure 2). In rowing, no deaths occurred due to the investigated causes. In athletics and swimming, there were significantly less deaths compared with the general population and there were 0.19 YS (95\% CI 0.06 to 0.32 ) and 0.19 YS (95\% CI 0.1 to 0.37$)$ respectively. There was no significant difference between fencing and the general population with -0.3 YS (95\% CI -1.11 to 0.5). Shooting showed a non-significant trend toward a higher risk with -2.49 YS (95\% CI -6.41 to 1.43) compared with the general population. All suicides in shooting were due to firearms $(n=3)$. Medalists and non-medalists had an equivalent risk regarding self-inflicted deaths $(\mathrm{p}=0.95)$ (Figure 3A).

\subsection{Deaths Attributed to Substance Abuse and Eating Disorders}

Substance abuse or an eating disorder were listed as the cause of death for 14 athletes (1 woman, 13 men). The most common mechanism of death was those related to alcohol abuse (Table 1) The risk of death was lower among Olympians compared to the general population resulting in a longevity advantage of 0.12 years $(95 \% \mathrm{CI} 0.08$ to 0.15$)$ (Figure 1CD). There was no significant difference in the risk of death by substance abuse or eating disorders for medalists compared to non-medalists $(\mathrm{p}=0.82)$ (Figure 3B).

\section{Discussion}

\subsection{Athletes vs the General Population}

This is the first study to investigate the risk of death due to mental disorders, substance abuse and suicides in former elite athletes across multiple sports compared with the general population. We demonstrated that former US Olympians followed similar mortality trends throughout the follow-up time compared with the general population but with diminished risks and a longevity advantage. This is similar to previous research on other causes of death, in which elite athletes demonstrated lower risks of dying from cancer and CVD [14,18-21] with an estimated 5-6 additional years for Finnish male elite athletes [21] and 6.5 years for French Olympians [14] of added longevity. 
Previous studies have shown an equivalent or higher prevalence of mental disorders in elite athletes including all stages and levels of symptoms [1-4]. It is not surprising that these disorders exist due to the pressure to excel [4], constant suffering from injuries or decreased performance, and all the changes faced upon retirement [1]. Substance abuse is also prevalent as it stems from binging during off-seasons or transitional distress at the end of athletes' careers [1]. Eating disorders could be attributed to sports requiring a lean body shape [2]. However, the factors that contribute to the existence of these disorders are most likely different to those that contribute to disorders that ultimately culminate in deaths. Using the mortality as an outcome allows us to have an entirely objective and quantifiable measure that may permit a greater understanding of severe mental disorders in elite athletes.

The lower risk of death in US Olympians compared with the general population is most likely attributable to a multitude of intertwined factors. Increased physical activity is associated with many positive outcomes, including mental health benefits. Individuals who engage in regular physical activity demonstrate a better quality of life, functional capacity, and mood state [22]. They display lower levels of anxiety and depression and an overall increase in general well-being [23]. Athletes score higher on questionnaires for a set of positive personality traits, including perseverance, positivity, resilience, self-esteem, and self-efficacy [24]. The explanation for this is likely bidirectional, with personality traits leading to sports involvement and participation in sports influencing personality development. A greater level of resilience, defined as the ability to adapt to the circumstances encountered [25], along with higher levels of positivity, self-esteem, and self-efficacy are associated with a better mental health $[6,26]$.

The social conditions of athletes could also contribute to a reduced risk of mortality from these mental causes by affording them more favorable lifestyles. For instance, a study in a cohort that ranged from pre-World War II to 1992 found that US Olympians were more likely to experience steep increases in socioeconomic status, with $60 \%$ reporting that being an Olympian aided them in their job acquisitions [27]. A higher socioeconomic status is associated with a lower rate of suicides [28], while disadvantaged neighbourhoods are linked to a higher prevalence of depression and substance abuse disorder [29]. Due to the prominent role that the college system plays in American sports, Olympians are more likely than the general population to attend and graduate from colleges [27]. A higher level of education has been associated with a lower rate of suicides [30], although there is some discrepancy within the literature [31].

Cohort selection effects have potential influences on the results. For instance, there are certain mental disorders that do not exist in the US Olympian population, which is why we chose to focus only on the most prevalent disorders instead of looking at mental disorders in general. Olympians could possess genetic and non-genetic predispositions that are more favourable, and have healthier lifestyle habits compared with the general population [32,33]. Once again, due to a possible bidirectional relationship with high-level sport, the lifestyles of these athletes could partially explain some of the demonstrated risk reduction from dying from a mental disorders or suicides.

\subsection{Athletic Performance and Risks}

Whilst the risk of death is lower, the fact that athletes exhibit deaths linked to suicides and mental disorders reinforces the notion that they are still vulnerable to the struggles faced by the general population. Mental disorders are physical conditions with physiological causes, and therefore they exist in all populations [34]. We found the same risk of death by such causes for medalists and non-medalists, demonstrating that the success of these athletes in their respective field does not affect their risks. There is still stigma associated with mental disorders, especially in the athletic culture, where athletes are expected to be mentally tough and resilient [35]. This could prevent them from seeking help when needed [36]. Continuing to have an open dialogue around mental health will be important for improving the attention these disorders receive both in the elite athlete population and in the general public.

\subsection{Access to Firearms}

Within the sports that had over 100 general deaths, shooting was the only sport to have a higher trend for suicides though it was not statistically significant. Deaths in this group were due to the use of firearms. While we cannot draw any definitive conclusions from this finding, the trend towards higher death rates in former shooters may be related to the access to guns and the surrounding issues related to the use of guns. These athletes are continually inserted into 
the gun debate ongoing in the US. An article leading to the Rio 2016 Olympic Games, stated that these Olympians are often the targets of media questioning, travel issues, and even death threats [37]. It is plausible that these added stressors, not faced by other athletes, could have an impact on shooters' well-beings.

\subsection{Strengths and Limitations}

The survival analyses performed in the present study were not adjusted by race, which would have allowed us to better characterize this cohort. As is the case for all observational studies, we cannot determine any causation effects, as we have no information on the lifestyle or physical activity habits of the Olympians after their retirement. Lastly, while it is the number of survivals that mainly drive the findings, the low number of deaths related to these illnesses limits the statistical power to compare the risk of death across all sports.

Our study is the first to determine the impact of mental disorders that culminate in death on US Olympians' longevity compared with the general population. This dataset includes verified data that were certified by national institutions. In addition, the century of collected data allows us to make strong conclusions. Lastly, we completed our analysis using the competing risk method, which provides accurate quantification of years-saved without censoring deaths from other causes.

\subsection{Conclusions and Future Perspectives}

We found a lower risk of mortality from mental health issues and suicides in former US Olympians, with a mortality reduction of $43 \%$. The risk was not different between the medalists and non-medalists. Except for shooting, which displayed higher trends of suicides, and fencing, with similar risks compared to the general population, most sports consistently showed lower risks of deaths from mental disorders and suicides. This novel finding requires replication in other elite populations and in a wider range of sports. The present findings also remind us that elite athletes, who can appear invincible to some, are not immune to these disorders and that an open, stigma-free dialogue is necessary on the topic of mental disorders and suicides.

\section{Declarations}

\subsection{Author Contributions}

SD: conceptualization, wrote manuscript, approved manuscript

HT: data collection, approved manuscript

QDL: data analysis, approved manuscript

JS: reviewed and approved manuscript

JFT: conceptualization, supervision, approved manuscript

JA: conceptualization, data analysis, reviewed, and approved manuscript

\subsection{Competing Interest and Funding}

None. 
5.3 Data Sharing

General population data is available from the websites listed in the methods section of this manuscript. Olympian data is not publicly available.

5.4 Ethical Approval

This study received ethics approval from the Institutional Review Board at the University of Texas at Austin (201503-0035). Data analyses and protection strictly adhered to the confidential data control plan based on the specifications set by the NDI. 
6. References

1 Gouttebarge V, Castaldelli-Maia JM, Gorczynski P, et al. Occurrence of mental health symptoms and disorders in current and former elite athletes: a systematic review and meta-analysis. Br J Sports Med 2019;53:700-6. doi:10.1136/bjsports-2019-100671

2 Rice SM, Purcell R, De Silva S, et al. The Mental Health of Elite Athletes: A Narrative Systematic Review. Sports Med Auckl NZ 2016;46:1333-53. doi:10.1007/s40279-016-0492-2

3 Åkesdotter C, Kenttä G, Eloranta S, et al. The prevalence of Mental Health Problems in elite athletes. J Sci Med Sport 2019;53. doi:10.1016/j.jsams.2019.10.022

4 Schaal K, Tafflet M, Nassif H, et al. Psychological Balance in High Level Athletes: Gender-Based Differences and Sport-Specific Patterns. PLOS ONE 2011;6:e19007. doi:10.1371/journal.pone.0019007

5 Baum A. Suicide in Athletes. In: Clinical Sports Psychiatry: An International Perspective. David Baron, Claudia Reardon, Steven Baron 2013. 79-88.

6 Armstrong S, Oomen-Early J. Social connectedness, self-esteem, and depression symptomatology among collegiate athletes versus nonathletes. J Am Coll Health J ACH 2009;57:521-6. doi:10.3200/JACH.57.5.521526

7 Rao AL, Asif IM, Drezner JA, et al. Suicide in National Collegiate Athletic Association (NCAA) Athletes: A 9Year Analysis of the NCAA Resolutions Database. Sports Health 2015;7:452-7. doi:10.1177/1941738115587675

8 Maron BJ, Haas TS, Murphy CJ, et al. Incidence and causes of sudden death in U.S. college athletes. $J$ Am Coll Cardiol 2014;63:1636-43. doi:10.1016/j.jacc.2014.01.041

9 Lehman EJ, Hein MJ, Gersic CM. Suicide Mortality Among Retired National Football League Players Who Played 5 or More Seasons. Am J Sports Med 2016;44:2486-91. doi:10.1177/0363546516645093

10 Lindqvist A-S, Moberg T, Ehrnborg C, et al. Increased mortality rate and suicide in Swedish former elite male athletes in power sports. Scand J Med Sci Sports 2014;24:1000-5. doi:10.1111/sms.12122

11 Woolf SH, Schoomaker H. Life Expectancy and Mortality Rates in the United States, 1959-2017. JAMA 2019;322:1996-2016. doi:10.1001/jama.2019.16932

12 Clarke PM, Walter SJ, Hayen A, et al. Survival of the fittest: retrospective cohort study of the longevity of Olympic medallists in the modern era. BMJ 2012;345:e8308. doi:10.1136/bmj.e8308

13 Wood AM, Kaptoge S, Butterworth AS, et al. Risk thresholds for alcohol consumption: combined analysis of individual-participant data for 599912 current drinkers in 83 prospective studies. The Lancet 2018;391:151323. doi:10.1016/S0140-6736(18)30134-X

14 Antero-Jacquemin J, Pohar-Perme M, Rey G, et al. The heart of the matter: years-saved from cardiovascular and cancer deaths in an elite athlete cohort with over a century of follow-up. Eur J Epidemiol 2018;33:531-43. doi:10.1007/s10654-018-0401-0

15 Allignol A, Schumacher M, Wanner C, et al. Understanding competing risks: a simulation point of view. BMC Med Res Methodol 2011;11:86. doi:10.1186/1471-2288-11-86

16 Andersen PK, Keiding N. Interpretability and importance of functionals in competing risks and multistate models. Stat Med 2012;31:1074-88. doi:10.1002/sim.4385 
17 Dignam JJ, Zhang Q, Kocherginsky M. The use and interpretation of competing risks regression models. Clin Cancer Res Off J Am Assoc Cancer Res 2012;18:2301-8. doi:10.1158/1078-0432.CCR-11-2097

18 Lemez S, Baker J. Do Elite Athletes Live Longer? A Systematic Review of Mortality and Longevity in Elite Athletes. Sports Med - Open 2015;1. doi:10.1186/s40798-015-0024-x

19 Antero-Jacquemin J, Rey G, Marc A, et al. Mortality in female and male French Olympians: a 1948-2013 cohort study. Am J Sports Med 2015;43:1505-12. doi:10.1177/0363546515574691

20 Garatachea N, Santos-Lozano A, Sanchis-Gomar F, et al. Elite athletes live longer than the general population: a meta-analysis. Mayo Clin Proc 2014;89:1195-200. doi:10.1016/j.mayocp.2014.06.004

21 Kettunen JA, Kujala UM, Kaprio J, et al. All-cause and disease-specific mortality among male, former elite athletes: an average 50-year follow-up. Br J Sports Med 2015;49:893-7. doi:10.1136/bjsports-2013-093347

22 Penedo FJ, Dahn JR. Exercise and well-being: a review of mental and physical health benefits associated with physical activity. Curr Opin Psychiatry 2005;18:189-93.

23 Stephens T. Physical activity and mental health in the United States and Canada: Evidence from four population surveys. Prev Med 1988;17:35-47. doi:10.1016/0091-7435(88)90070-9

24 Laborde S, Guillén F, Mosley E. Positive personality-trait-like individual differences in athletes from individualand team sports and in non-athletes. Psychol Sport Exerc 2016;26:9-13. doi:10.1016/j.psychsport.2016.05.009

25 Connor KM, Davidson JRT. Development of a new resilience scale: The Connor-Davidson Resilience Scale (CD-RISC). Depress Anxiety 2003;18:76-82. doi:10.1002/da.10113

26 Srivastava K. Positive mental health and its relationship with resilience. Ind Psychiatry J 2011;20:75-6. doi:10.4103/0972-6748.102469

27 Eisen G, Turner D. Myth \& Reality: Social Mobility of the American Olympic Athletes. Int Rev Sociol Sport 1992;27:165-74. doi:10.1177/101269029202700206

28 Rehkopf DH, Buka SL. The association between suicide and the socio-economic characteristics of geographical areas: a systematic review. Psychol Med 2006;36:145-57. doi:10.1017/S003329170500588X

29 Silver E, Mulvey EP, Swanson JW. Neighborhood structural characteristics and mental disorder: Faris and Dunham revisited. Soc Sci Med 2002;55:1457-70. doi:10.1016/S0277-9536(01)00266-0

30 Abel EL, Kruger ML. Educational Attainment and Suicide Rates in the United States. Psychol Rep 2005;97:258. doi:10.2466/pr0.97.1.25-28

31 Pompili M, Vichi M, Qin P, et al. Does the level of education influence completed suicide? A nationwide register study. J Affect Disord 2013;147:437-40. doi:10.1016/j.jad.2012.08.046

32 Bäckmand H, Kujala U, Sarna S, et al. Former athletes' health-related lifestyle behaviours and self-rated health in late adulthood. Int J Sports Med 2010;31:751-8. doi:10.1055/s-0030-1255109

33 Kujala UM, Kaprio J, Sarna S, et al. Relationship of leisure-time physical activity and mortality: the Finnish twin cohort. JAMA 1998;279:440-4. doi:10.1001/jama.279.6.440

34 Summergrad P. Investing in global mental health: the time for action is now. Lancet Psychiatry 2016;3:390-1. doi:10.1016/S2215-0366(16)30031-1 
35 Bauman NJ. The stigma of mental health in athletes: are mental toughness and mental health seen as contradictory in elite sport? Br J Sports Med 2016;50:135-6. doi:10.1136/bjsports-2015-095570

36 Corrigan PW, Druss BG, Perlick DA. The Impact of Mental Illness Stigma on Seeking and Participating in Mental Health Care. Psychol Sci Public Interest J Am Psychol Soc 2014;15:37-70. doi:10.1177/1529100614531398

37 Marshall J. Olympic shooters thrust into gun-control debate. AP News. 2016.https://apnews.com/49ad93e67a1346778f356f7bc4d2bda0 
Table 1: Description of the detailed causes of death obtained via the National Death Index

\begin{tabular}{|l|l|l|l|}
\hline Causes of deaths & & Detailed causes & N (women) \\
\hline \multirow{4}{*}{$\begin{array}{l}\text { Self-Harm, } \\
\text { Anxiety, and } \\
\text { Depression }\end{array}$} & Suicide by firearms & 12 \\
& Self-Harm & Intentional self-poisoning & $8(1)$ \\
\cline { 2 - 5 } & $\begin{array}{l}\text { Anxiety and } \\
\text { Depression }\end{array}$ & Others & 9 \\
\hline \multirow{2}{*}{$\begin{array}{l}\text { Substance } \\
\text { Abuse and } \\
\text { Eating } \\
\text { Disorders }\end{array}$} & $\begin{array}{l}\text { Substance } \\
\text { Abuse }\end{array}$ & $\begin{array}{l}\text { Alcoholic liver disease } \\
\text { or tobacco disorders not classified elsewhere }\end{array}$ & $1(1)$ \\
\cline { 2 - 5 } & $\begin{array}{l}\text { Eating } \\
\text { Disorders }\end{array}$ & Onspecified eating disorders & 8 \\
\hline
\end{tabular}


Figure 1. A. Cumulative probability of death by self-harm, anxiety, and depression among US Olympians (teal area) in comparison with the general population (black line). Figure 1B. The years-saved among US Olympians (thick line) and the $95 \% \mathrm{CI}$ (thinner lines) due to death by self-harm, anxiety, and depression. Figure 1C: Cumulative probability of death by substance abuse and eating disorders among US Olympians (teal area) in comparison with the general population (black line). Figure 1D. The years-saved among US Olympians (thick line) and the $95 \%$ CI (thinner lines) due to death by substance abuse and eating disorders. 

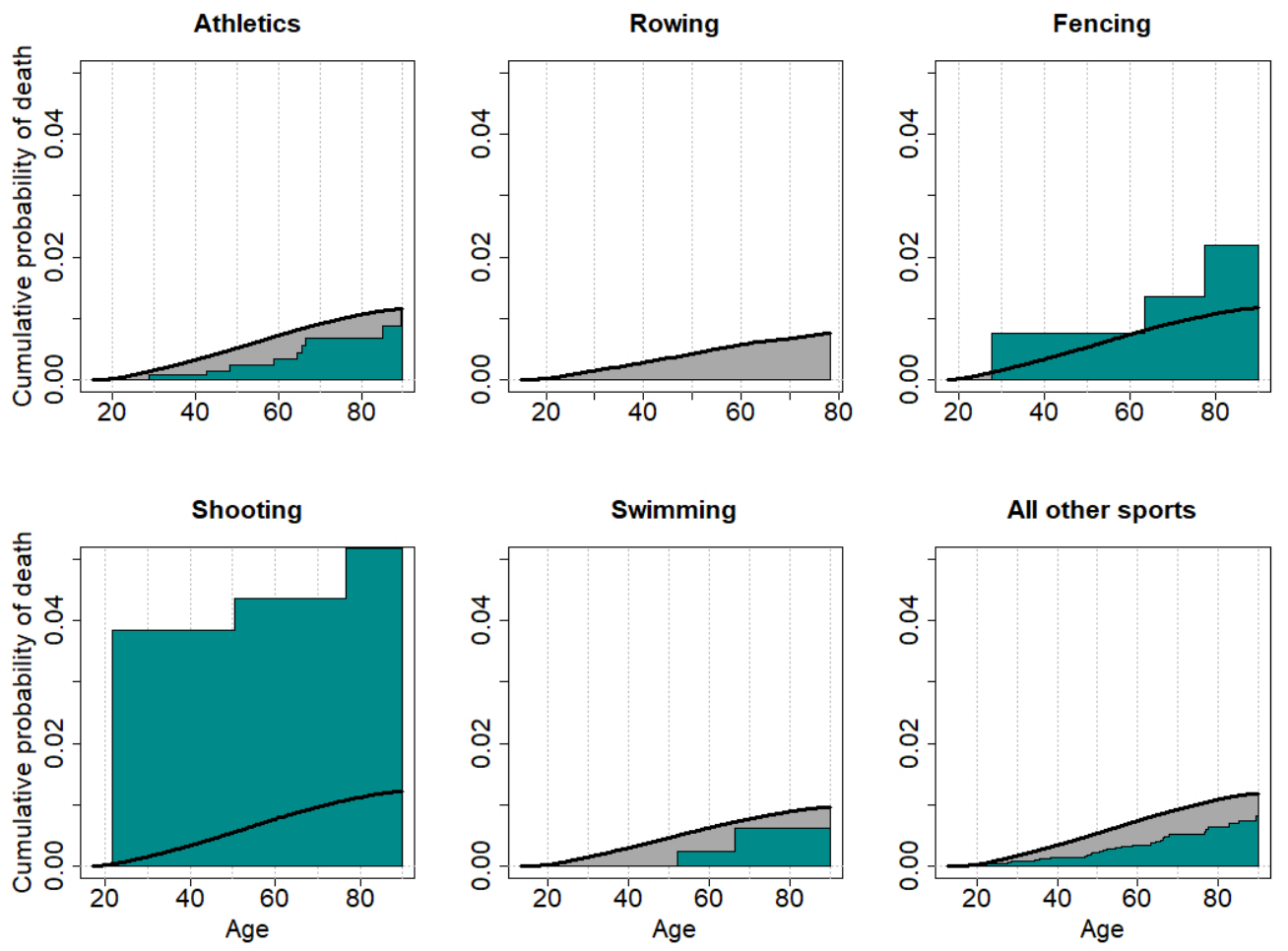

Figure 2. Cumulative probability of death by self-harm, anxiety, and depression stratified by sports among US Olympians (teal area) in comparison with the general population (black line) for sports with over 100 total general deaths.

$277 \times 210 \mathrm{~mm}(96 \times 96 \mathrm{DPI})$ 

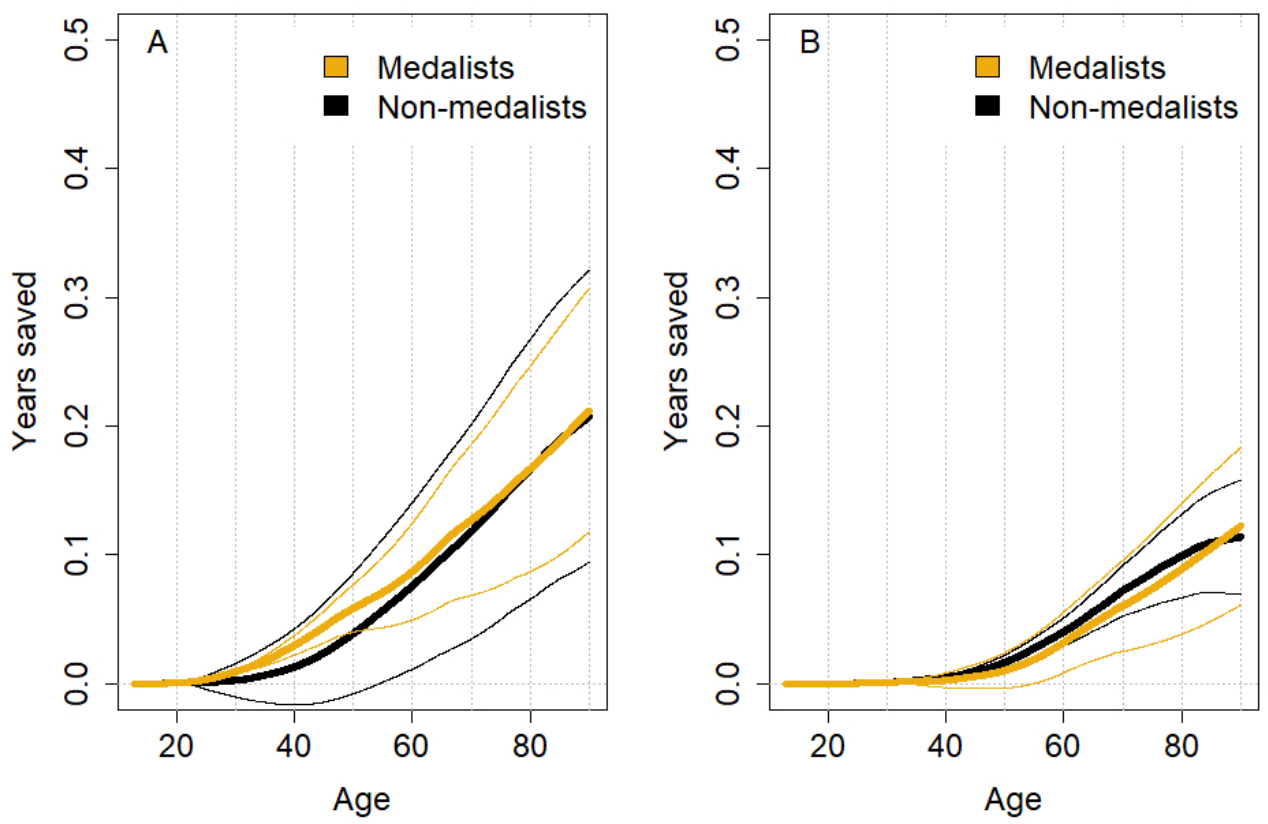

Figure 3. A. The years-saved among Olympic medalists (thick yellow line) and the 95\% CI (thinner yellow lines) compared to non-medallists (thick black line) and 95\% CI (thinner black lines) for the causes of selfharm, anxiety, and depression. B. The years-saved among Olympic medalists (thick yellow line) and the 95\% CI (thinner yellow lines) compared to non-medallists (thick black line) and 95\% CI (thinner black lines) for the causes of substance abuse and eating disorders. 


\begin{tabular}{|c|c|c|c|c|c|c|}
\hline & \multicolumn{2}{|l|}{ ICD-8 } & \multicolumn{2}{|l|}{ ICD-9 } & \multicolumn{2}{|l|}{ ICD-10 } \\
\hline & Code & Description & Code & Description & Code & Description \\
\hline \multirow{15}{*}{$\begin{array}{c}\text { Substance } \\
\text { Abuse }\end{array}$} & 291 & Alcoholic psychosis & 291 & Alcoholic psychosis & F10 & Use of alcohol \\
\hline & 294.3 & $\begin{array}{l}\text { Psychosis associated with drug or } \\
\text { poison }\end{array}$ & 292 & Drug psychosis & F11 & Use of opioids \\
\hline & 303 & Alcoholism & 303 & Alcohol dependence syndrome & F12 & Use of cannabinoids \\
\hline & 393 & Other/unspecified alcoholism & 304 & Drug dependence & F13 & Use of sedatives or hypnotics \\
\hline & 304 & Drug dependence & 305 & Drug abuse & F14 & Use of cocaine \\
\hline & 571 & Alcoholic cirrhosis & 357.5 & Alcoholic polyneuropathy & F15 & $\begin{array}{l}\text { Use of other stimulants including } \\
\text { caffeine }\end{array}$ \\
\hline & & & 357.6 & Drugs polyneuropathy & F16 & Use of hallucinogens \\
\hline & & & 425.5 & Alcoholic cardiomyopathy & F17 & Use of tobacco \\
\hline & & & 535.3 & Alcoholic gastritis & F18 & Use of volatile solvents \\
\hline & & & 571.0 & Alcoholic fatty liver & F19 & $\begin{array}{l}\text { Multiple drug use or use of other } \\
\text { psychoactive substances }\end{array}$ \\
\hline & & & 571.1 & Acute alcoholic hepatitis & G62.0 & Alcoholic polyneuropathy \\
\hline & & & 571.2 & Alcohol cirrhosis of liver & G62.1 & Drug-induced polyneuropathy \\
\hline & & & 571.3 & Alcohol liver damage unspecified & I42.6 & Alcoholic cardiomyopathy \\
\hline & & & & & K29.20 & $\begin{array}{l}\text { Alcoholic gastritis without } \\
\text { bleeding }\end{array}$ \\
\hline & & & & & K70 & Alcoholic liver disease \\
\hline \multirow{3}{*}{$\begin{array}{c}\text { Eating } \\
\text { Disorders }\end{array}$} & 306.5 & Feeding disturbance & 307.1 & Anorexia nervosa & F50 & Eating disorders \\
\hline & & & 307.5 & Other eating disorders & R63.0 & Anorexia \\
\hline & & & 783 & Anorexia & & \\
\hline \multirow{6}{*}{$\begin{array}{l}\text { Anxiety and } \\
\text { Depression }\end{array}$} & 296 & Affective psychoses & 296 & Affective psychoses & F30 & Manic episodes \\
\hline & 298 & Depressive psychoses & 298 & Depressive psychoses & F31 & Bipolar affective disorder \\
\hline & 300.0 & Neurotic disorders & 300 & Neurotic disorders & F32 & Depressive episode \\
\hline & 300.4 & Depressive neurosis & 309 & Adjustment reaction & F33 & Recurrent depressive episode \\
\hline & 790.2 & Nervousness and debility & 311 & Depressive disorder & F40 & Phobic anxiety disorders \\
\hline & 309.1 & $\begin{array}{l}\text { Mental disorders not specified as } \\
\text { psychosis associated with physical } \\
\text { conditions with drug, poison, or } \\
\text { systemic intoxication }\end{array}$ & & & F41 & Other anxiety disorders \\
\hline Self-Harm & $\begin{array}{l}\text { E950- } \\
\text { E959 }\end{array}$ & Intentional self-harm & $\begin{array}{l}\text { E950- } \\
\text { E959 }\end{array}$ & Intentional self-harm & $\begin{array}{l}\text { X71- } \\
\text { X83 }\end{array}$ & Intentional self-harm \\
\hline
\end{tabular}

